\title{
Assessing Burned Areas in Wildfires and Prescribed Fires with Spectral Indices and SAR Images in the Margalla Hills of Pakistan
}

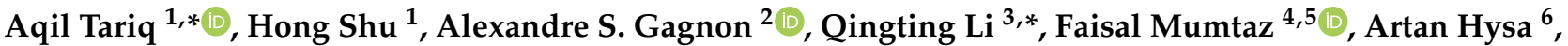 \\ Muhammad Amir Siddique ${ }^{7}$ and Iqra Munir ${ }^{1}$
}

check for

updates

Citation: Tariq, A.; Shu, H.; Gagnon, A.S.; Li, Q.; Mumtaz, F.; Hysa, A.;

Siddique, M.A.; Munir, I. Assessing

Burned Areas in Wildfires and

Prescribed Fires with Spectral Indices and SAR Images in the Margalla Hills of Pakistan. Forests 2021, 12, 1371. https: / / doi.org/10.3390/f12101371

Academic Editor:

Venceslas Goudiaby

Received: 18 June 2021

Accepted: 1 October 2021

Published: 9 October 2021

Publisher's Note: MDPI stays neutral with regard to jurisdictional claims in published maps and institutional affiliations.

Copyright: (c) 2021 by the authors. Licensee MDPI, Basel, Switzerland. This article is an open access article distributed under the terms and conditions of the Creative Commons Attribution (CC BY) license (https:// creativecommons.org/licenses/by/ $4.0 /)$.
1 State Key Laboratory of Information Engineering in Surveying, Mapping and Remote Sensing (LIESMARS), Wuhan University, Wuhan 430079, China; shu_hong@whu.edu.cn (H.S.); munir-iqra@whu.edu.cn (I.M.)

2 School of Biological and Environmental Sciences, Liverpool John Moores University, Liverpool L3 3AF, UK; a.gagnon@ljmu.ac.uk

3 Airborne Remote Sensing Center, Aerospace Information Research Institute, Chinese Academy of Sciences, Beijing 100094, China

4 State Key Laboratory of Remote Sensing Sciences, Aerospace Information Research Institute, Chinese Academy of Sciences, Beijing 100101, China; faisal@aircas.ac.cn

5 University of Chinese Academy of Sciences (UCAS), Beijing 101408, China

6 Faculty of Engineering and Architecture, Epoka University, 1032 Tirana, Albania; ahysa@epoka.edu.al

7 School of Landscape Architecture, Tianjin University, Tianjin 300072, China; amir@tju.edu.cn

* Correspondence: aqiltariq@whu.edu.cn (A.T.); liqt@radi.ac.cn (Q.L.)

\begin{abstract}
The extent of wildfires cannot be easily mapped using field-based methods in areas with complex topography, and in those areas the use of remote sensing is an alternative. This study first obtained images from the Sentinel-2 satellites for the period 2015-2020 with the objective of applying multi-temporal spectral indices to assess areas burned in wildfires and prescribed fires in the Margalla Hills of Pakistan using the Google Earth Engine (GEE). Using those images, the Normalized Difference Vegetation Index (NDVI) and the Normalized Burn Ratio (NBR), which are often used to assess the severity of fires, were calculated for wildfires and prescribed fires. For each satellite image, spectral indices values were extracted for the 5th, 20th, 40th, 60th, 80th and 95th percentiles of pixels of each burned area. Then, boxplots representing the distribution of these values were plotted for each satellite image to identify whether the regeneration time subsequent to a fire, also known as the burn scar, and the severity of the fire differed between the autumn and summer wildfires, and with prescribed fires. A statistical test revealed no differences for the regeneration time amongst the three categories of fires, but that the severity of summer wildfires was significantly different from that of prescribed fire, and this, for both indices. Second, SAR images were obtained from the Sentinel-1 mission for the same period as that of the optical imagery. A comparison of the response of 34 SAR variables with official data on wildfires and prescribed fires from the Capital Development Authority revealed that the 95th percentile of the Normalized Signal Ratio (NSR p_95) was found to be the best variable to detect fire events, although only $50 \%$ of the fires were correctly detected. Nonetheless, when the occurrence of fire events according to the SAR variable NSR p_95 was compared to that from the two spectral indices, the SAR variable was found to correctly identify 95\% of fire events. The SAR variable NSR p_95 is thus a suitable alternative to spectral indices to monitor the progress of wildfires and assess their severity when there are limitations to the use of optical images due to cloud coverage or smoke, for instance.
\end{abstract}

Keywords: wildfires; prescribed fires; Margalla Hills; SAR; optical images; spectral indices; NBR; NDVI

\section{Introduction}

Wildfires are a common natural occurrence in many environments and constitute a vital component for their management. However, fires of high severity that cause devasting 
impacts over large areas have recently been documented, notably in the United States of America, the Mediterranean region, Australia, and Pakistan [1-5], bringing into question the effectiveness of current management practices, as these severe wildfires lead to an undesirable alteration and degradation of the landscape [6]. Many variables influence the severity of a fire, including elevation, slope and aspect [7], weather and climatic conditions [8], the structural characteristics of the forest, such as the density of trees and their diameter [9], and the history of fires in the area [10]. The last factor is particularly important, as it affects the soil's organic content, which fuels the fire. For this reason, fuel treatments such as vegetation thinning and prescribed fires are commonly conducted in order to alter fuel conditions and thus make wildfires less severe [11].

The severity level of large fires cannot easily be mapped using field-based methods, especially in areas with complex topography. Hence, remote sensing provides an opportunity to assess the impact of wildfires. This is because a fire leads to changes in vegetation and soil moisture, enabling the use of optical remote sensing images to assess its impact [12,13]. Moreover, with the increase in their spatial resolution, satellite data and their derived products have made it possible not only to determine the spatial extent of the burned area as a result of a fire, but also to provide valuable information for monitoring the progression of wildfires and to assess their severity [14,15].

Optical images from the Sentinel-2 satellite, with a 10-m spatial resolution, together with spectral indices have previously been used to assess fire severity. The most commonly used indices for this purpose are the Normalized Burn Ratio (NBR) and the Normalized Difference Vegetation Index (NDVI) [16,17], with the results of previous research identifying NBR to be more sensitive than NDVI to the spectral changes produced by fires of moderate and extreme severity $[18,19]$. Although it was found that optical imagery can satisfactorily be used to monitor and assess the severity of a fire, there are limitations with regard to their use, such as cloud coverage, smoke and haze, all of which limit the usefulness of sensors in the visible and infrared domains of the electromagnetic spectrum. Moreover, optical images from Landsat, with its 16-day repeat cycle, is a limitation for the monitoring of burned areas. In addition, misinterpretation of burned areas with dark soils, shaded regions and water bodies is common when using optical satellite imagery [20,21].

Satellite images from the Sentinel-1 mission provide a potential alternative to optical images in situations when the latter cannot be used due to cloud coverage or smoke, for instance, or they can complement the optical images to gain more information from the surface [22]. The Sentinel-1 mission provides C-band Synthetic Aperture Radar (SAR) images [23], and satellite images from that mission as well as those from the Sentinel-2 mission are available in the Google Earth Engine (GEE), an integrated platform designed to empower traditional remote sensing scientists and a wider audience [24] by providing pre-processed satellite data free of charge.

The mapping of burned areas using SAR images relies on changes in the backscattering of the radar signal, which varies depending of the severity of the fire [3,22]. C-band SAR data have previously been used to investigate the extent of burned areas subsequent to fires in Australia and California, and it was found that the vertical horizontal (VH) polarization responded well to the occurrence of fires $[3,22]$. Other studies have also found that SAR imagery allowed for the detection and extent of burn scars in the landscape [25-28]. Previous research has thus found that SAR provides an opportunity for detecting and assessing the spatial extent and damage of wildfires without the limitations of atmospheric conditions on their use, such as for remote sensing images in the optical range. Nonetheless, further research is needed to assess the functionality associated with the use of those images and how the damage assessment from wildfires using SAR images compares with that using spectral indices.

Therefore, this study assesses areas burned in wildfires and prescribed fires using optical (Sentinel-2) images, and the associated spectral indices typically used for that purpose, and SAR (Sentinel-1) images. Specifically, the objectives are (1) to determine whether there are significant differences in the backscatter signal of the Sentinel-1 images 
during wildfires and prescribed fires for their use in detecting burned areas and fire severity, as well as to identify the best variable to detect burned areas when working with SAR images, (2) to compare fire severity from fires as identified by SAR images versus that from spectral indices, and (3) to determine whether the severity of the prescribed fires is significantly different from that of wildfires, with a focus on the summer and autumn seasons. This research evaluates fire severity based on vegetation recovery following a fire only, hence a longer recovery period would be associated with a more severe fire.

\section{Materials and Methods}

\subsection{Study Area}

This study was conducted in the Margalla Hills of Pakistan (Figure 1), a region 15,883 hectares in size covering forests, grass and small bushes inhabited by the Genista tribe. The region is not used as pasture and is regularly affected by fires [29]. The climate of the region is subtropical; the average maximum summer temperature is $34.3^{\circ} \mathrm{C}[4,5,30]$, and total annual precipitation is, on average, $1200 \mathrm{~mm}[28,31,32]$, the majority of which falls in July and August. Accordingly, the fire season occurs between May and July, when the temperatures are warmest and before the beginning of the monsoonal rains $[4,5,13,33]$. Lightning and the hot and dry weather during the summer months combined with the dry conditions in the autumnal months of September and October after the monsoon season are the natural and primary causes for the ignition and spread of wildfires, while anthropogenic causes coming in second place in reports of past fire incidents [34-36].

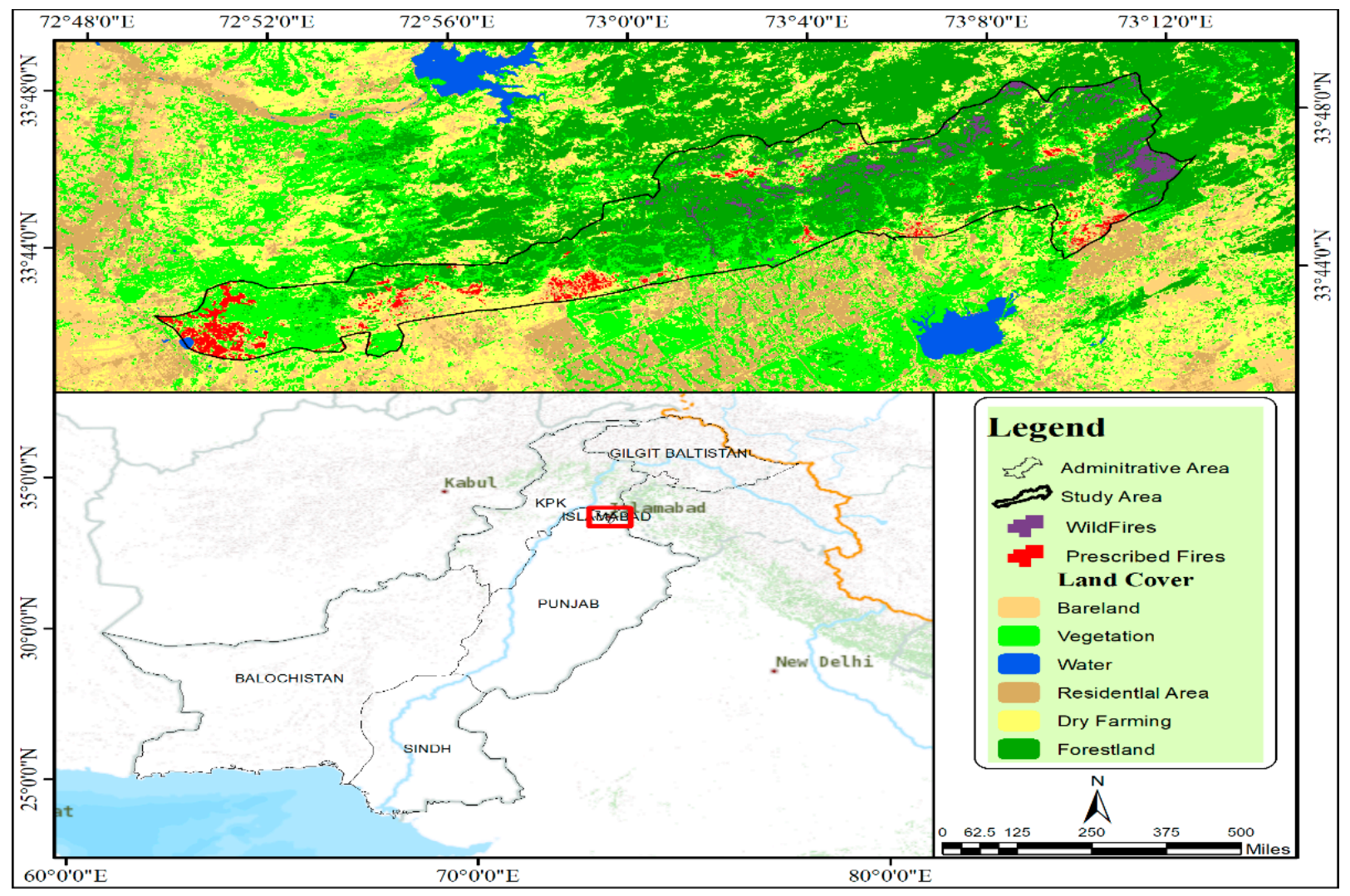

Figure 1. Occurrence of wildfires and prescribed fires during the period 2015-2020 in the Margalla Hills of Pakistan.

\subsection{Datasets}

Data on the occurrence of wildfires and prescribed fires that took place during the period 2015-2020 in the study region were collected from the website of the Capital Development Authority (https:/ / gis.cda.gov.pk/isl/; accessed on 18 February 2020) (CDA, 2020), with the attribute table of the dataset containing information such as the date of the 
fire, its cause, and the total area burned [4]. Wildfires with an incomplete attribute table were not considered in this study. The CDA also provided data on land-use and land-cover (LULC) type for the year 2018 at a $0.5 \mathrm{~m}$ resolution. Data from 30 prescribed fires, also during the 2015-2020 period, were also obtained from the CDA (Figure 1). The prescribed fires ranged in spatial extent from one to three hectares. The data on prescribed fires were provided in shapefile format, containing both qualitative and quantitative information; the latter describing the burned areas and the former the behavior and impacts of the fire. The prescribed fire dataset also included information such as the slope of the area where the fires took place as well as the aspect, altitude, and the date when the area burned.

\subsection{Sampling and Preprocessing}

Polygons from Sentinel-1 and Sentinel-2 images less than one hectare and with a distance from border less than $10 \mathrm{~m}$ were removed from the study to reduce border impacts. This value of $10 \mathrm{~m}$ was selected given the $10 \mathrm{~m}$ spatial resolution of the Sentinel-2 images. After that, an inner buffer of $10 \mathrm{~m}$ was added to the remaining polygons for the Sentinel-1 and Sentinel 2 analysis. Following the creation of this inner buffer zone, the number of pixels for each polygon was checked, and polygons with less than five pixels were not considered, resulting in more robust statistics that are less susceptible to outliers. For Sentinel 1, all 10 polygons had more than 20 pixels and therefore could be used, while for Sentinel-2 (Table 1), 10 polygons could also be analysed. The analysis returned 48 images for Sentinel 1 between 24 April 2015 and 31 December 2020 and 70 images between 11 May 2015 and 2 August 2020 for Sentinel-2.

Table 1. Number of pixels for each polygon for the Sentinel-1 and Sentinel-2 images.

\begin{tabular}{cccc}
\hline \multicolumn{2}{c}{ Sentinel-1 } & \multicolumn{2}{c}{ Sentinel-2 } \\
\hline Polygon Name & Number of Pixel & Polygon Name & Number of Pixels \\
\hline Summer_18_1 & 1294 & Summer_18_1 & 1294 \\
Summer_19_1 & 518 & Summer_19_6 & 1929 \\
Summer_19_3 & 1930 & Summer_19_12 & 516 \\
PF_18_1 & 158 & PF_18_1 & 152 \\
PF_18_6 & 223 & PF_18_6 & 220 \\
PF_18_12 & 1178 & PF_18_12 & 1160 \\
PF_19_1 & 580 & PF_19_1 & 581 \\
Autumn_18_2 & 27 & Autumn_18_2 & 33 \\
Autumn_19_1 & 39 & Autumn_19_1 & 48 \\
Autumn_20_6 & 46 & Autumn_20_6 & 58 \\
\hline
\end{tabular}

(Note: The polygon name refers to the "season_year_sample number").

Because clouds can prevent radiation from active fires from reaching the thermal sensors on satellites, the algorithm was designed with a backup approach to deal with the lack of flames for a particular land cover type and detection period. However, in order for the approach to work, flames for each land cover class must be present at some point during the fire season being examined.

\subsection{Analysis}

\subsubsection{Sentinel-1 Images Using GEE}

The pre-processing step includes Ground Range Detected (GRD) data downloaded from GEE and radiometric normalization to gamma nought $\left(\gamma^{0}\right)$ using the gamma nought lookup table provided in the product metadata. Over land, only SAR images collected in the interferometric broad swath mode, the default acquisition mode of Sentinel-1, were used. Using elevation data from the Shuttle Radar Topography Mission (SRTM) one-arcsecond DEM and the bicubic interpolator, the calibrated images were orthorectified to ground geometry as in $[37,38]$. The orthorectified images were clipped to the processing tile, and data collected along the same orbital route but in separate slices were mosaicked (i.e., slice assembly). The burned area algorithm uses temporal backscatter differences of 
the same relative orbit, so terrain-flattening $[39,40]$ was not required because the DEMderived normalization (illumination) area for a given pixel is constant in time, so the preto post-fire backscatter coefficient variations are not affected. The GEE product was then converted to provide $\gamma^{0}$ values, which corrected for the local incidence angle in SRTM and removed the bias between ascending and descending orbits that was visible in the plots.

A temporal decorrelation between fire events and backscatter coefficient change was discovered during the algorithm development [39]. Such decorrelation events could be the result of a delay in the decrease of the backscatter signal after the fire due to a variety of factors, notably: (1) pre-fire conditions, such as drier than usual weather, which could result in low values for the pre-fire backscatter coefficient; (2) post-fire weather, such as precipitation, which could temporally increase the backscatter coefficient; and (3) vegetation-dependent backscatter response to fire. VH backscatter reduction may be delayed in forested areas, for example, since there are still enough scattering components (tree trunks and branches) present following a fire. Trunks and branches dry out with time, resulting in less vegetation backscatter.

This subsection discusses the behavior of the C-band backscatter coefficient after fire occurrences in order to better understand the proposed algorithm, its development, and the decision-making process that led to it. Depending on the polarization, the surviving vegetation, and the climatic conditions (i.e., temperature and rainfall) at the time that the SAR image was taken, fire in vegetated regions can cause either an increase or decrease in the backscatter coefficient.

Backscatter values may be used as a signal in analysis to identify a significant difference from the background noise. The natural fluctuation of backscatter across many detections may be considered to represent noise. GEE was used to derive six percentiles for each polygon. Outliers and null values may come from regions on the edge of an image, even if they are inside the image footprint. Within the footprint, the image/area pair utilized in the map reduce process will be included, but null or extremely low values will be produced, which must be deleted.

The values extracted by "map reduce" were six percentiles $P n=\{\mathrm{p} 5, \mathrm{p} 20, \mathrm{p} 40, \mathrm{p} 60$, p80 and p95\}. These were available for both $V V$ and $V H$ polarizations. The following Equations (1)-(5) were used for the SAR percentile analysis:

$$
\begin{gathered}
I P r 1=Y_{p 75}-Y_{p 25} \\
I P r 2=Y_{p 90}-Y_{p 10} \\
N S R_{p n}=\frac{Y_{p n}^{V V}-Y_{p n}^{V H}}{Y_{p n}^{V V}+Y_{p n}^{V H}} \\
R A T I O_{p n}=\frac{Y_{p n}^{V V}}{Y_{p n}^{V H}} \\
D I F F_{p n}=Y_{p n}^{V V}-Y_{p n}^{V H}
\end{gathered}
$$

where: $P$ is the percentile and $n=$ (5th, 20th, 40th, 60th, 80th, 95th); NSR is Normalized Signal Ratio (NSR); IPr 1 and IPr2 are Inter Percentile range for the 20th 80th and the 5th to 95th ranges, respectively. Thirty four variables were tested, and the explanation for each one of them is presented in Table 2. Six major $V H$ and $V V$ polarization over the percentiles were extracted from the Sentinel-1 data.

To account for temporal decorrelation and enhance identification results over difficult land cover such as vegetation regions, post-processing was required. After that, this technique was used to choose one or a few of the best variables to compare them to the spectral indices, since comparing all variables to the spectral indices would be a daunting task. 
Table 2. The 34 variables used to analyze SAR data.

\begin{tabular}{|c|c|}
\hline Name of Variables & Explanation \\
\hline $\begin{array}{l}\text { VH_p5; VH_p20; VH_p40; VH_p60; VH_p80; } \\
\text { VH_p95 }\end{array}$ & $\begin{array}{l}\text { VH polarization over various percentiles taken } \\
\text { directly from the Sentinel-1 database in GEE }\end{array}$ \\
\hline VH Range_p80p20; VH Range_p95p5 & Inter-percentile ranges over $\mathrm{VH}$ polarization \\
\hline $\begin{array}{l}\text { VV_p5; VV_p20;VV_p40; VV_p60;VV_p80; } \\
\text { VV_p95 }\end{array}$ & $\begin{array}{l}\text { VV polarization over the six percentiles taken } \\
\text { directly from the Sentinel-1 database in GEE }\end{array}$ \\
\hline $\begin{array}{l}\text { VVdivVH_p5; VVdivVH_p20; VVdivVH_p40; } \\
\text { VVdivVH_p60; VVdivVH_p80; VVdivVH_p95 }\end{array}$ & RATIO over the six percentiles \\
\hline $\begin{array}{l}\text { VVminusVH_p5; VVminusVH_p20; } \\
\text { VVminusVH_p40; VVminusVH_p60; } \\
\text { VVminusVH_p80; VVminusVH_p95 }\end{array}$ & DIFF over the six percentiles \\
\hline $\begin{array}{l}\text { VVnormDiffVH_p5; VVnormDiffVH_p20; } \\
\text { VVnormDiffVH_p40; VVnormDiffVH_p60; } \\
\text { VVnormDiffVH_p80; VVnormDiffVH_p95 }\end{array}$ & NSR over the six percentiles \\
\hline VVRange_p80p20; VVRange_p95p5 & Inter-percentile ranges over VV polarization \\
\hline
\end{tabular}

The smoothed Z-score method, as described in [41], was used for data evaluation to identify backscatter levels that differ substantially from "normal" values. Backscatter values, by giving a consistent surface feature across time, are thought to give a regularly distributed population with a particular average and standard deviation. The method must account for snow and rain, which alter the surface characteristics and may lead to false positives. The detection method employs a Z-score derived from the average $(\mu)$ and standard deviation $(\sigma)$ of values preceding the value to be tested across a moving window $p$ of size $N$. The backscatter value may be substantially different from previous readings if $\mathrm{Z}$ is over a particular threshold. We utilized three criteria to obtain a confidence level of $99 \%$ or higher. This method is utilized in a variety of applications, including detecting acceleration [42] and recognizing ribosome footprint anomalies [43].

\subsubsection{Validation of the Spectral Indices}

The following spectral indices were calculated using Sentinel-2 images: NDVI (Equation (6)), NBR (Equation (7)), and delta NBR (dNBR) (Equation (8)), because they are the most common indices to assess the severity of a fire in the literature [18].

$$
N D V I=\frac{\left(\text { Band }^{R E D}-B^{R a n d} d^{N I R}\right)}{\left(B a n d^{R E D}+B a n d^{N I R}\right)}
$$

where NIR refers to the near-infrared, Band ${ }^{N I R}$ denotes $0.76-0.90 \mu \mathrm{m}$ wavelengths,

$$
N B R=\frac{\left(\text { Band }^{N I R}-B_{a n d}{ }^{S W I R}\right)}{\left(B a n d^{N I R}+B a n d^{S W I R}\right)}
$$

where SWIR refers to short wave infrared and Band ${ }^{S W I R}$ refers to wavelengths in the following range: $2.09-2.35 \mu \mathrm{m}$. The NDVI and NBR values vary from -1 to 1 , with 1 representing the greatest level of vegetative activity, and negatives values and those close to zero indicating little or no chlorophyll activity [24,44]. Burned frequency and severity are determined by differentiating between these two index layers:

$$
d N B R=\left(N B R^{\text {Pre-fire }}-N B R^{\text {Post-fire }}\right)
$$

A high $d N B R$ value indicates a more severe fire and negative values suggest decreased vegetation productivity subsequent to a fire. "Non-processing zones" contains portions of the background covered by fog or haze or wet areas. Field survey data based on the Normalized Burned Ratio-Field survey Data (NBR-FD) as provided by CDA, were also used to calculate the burned area after a forest fire. Normalized Burned Ratio-Sentinel-1 
data (NBR-S1), Normalized Burned Ratio-Sentinel-2 data (NBR-S2), Delta Normalized Burned Ratio-Sentinel-1 data (dNBR-S1), Delta Normalized Burned Ratio-Sentinel-2 data (dNBR-S2), Delta Normalized Burn Ratio- Field survey Data ( $d N B R-F D)$ were extracted from the pre and post fire field survey difference and both files (NBR and $d N B R$ ) were provided to us in the form of shape files of the burned area.

Processed satellite data and the CDA field data were grouped into two clusters. The first cluster shows the calculated indices of NDVI, NBR and dNBR, and the second cluster used ground field derived data including NBR-FD and dNBR-FD. Correlation matrices between Sentinel images and CDA field data were computed. Correlation coefficients with absolute values greater than 0.6 were tallied within the field and image categories were named by sensor type and strength of the Pearson's correlation coefficient.

After obtaining the Sentinel-1 data as well as the NDVI and NBR plots from the Sentinel-2 images, a comparison was conducted to see whether SAR provides a suitable signal during a fire occurrence. Figure 2 summarizes the approach.

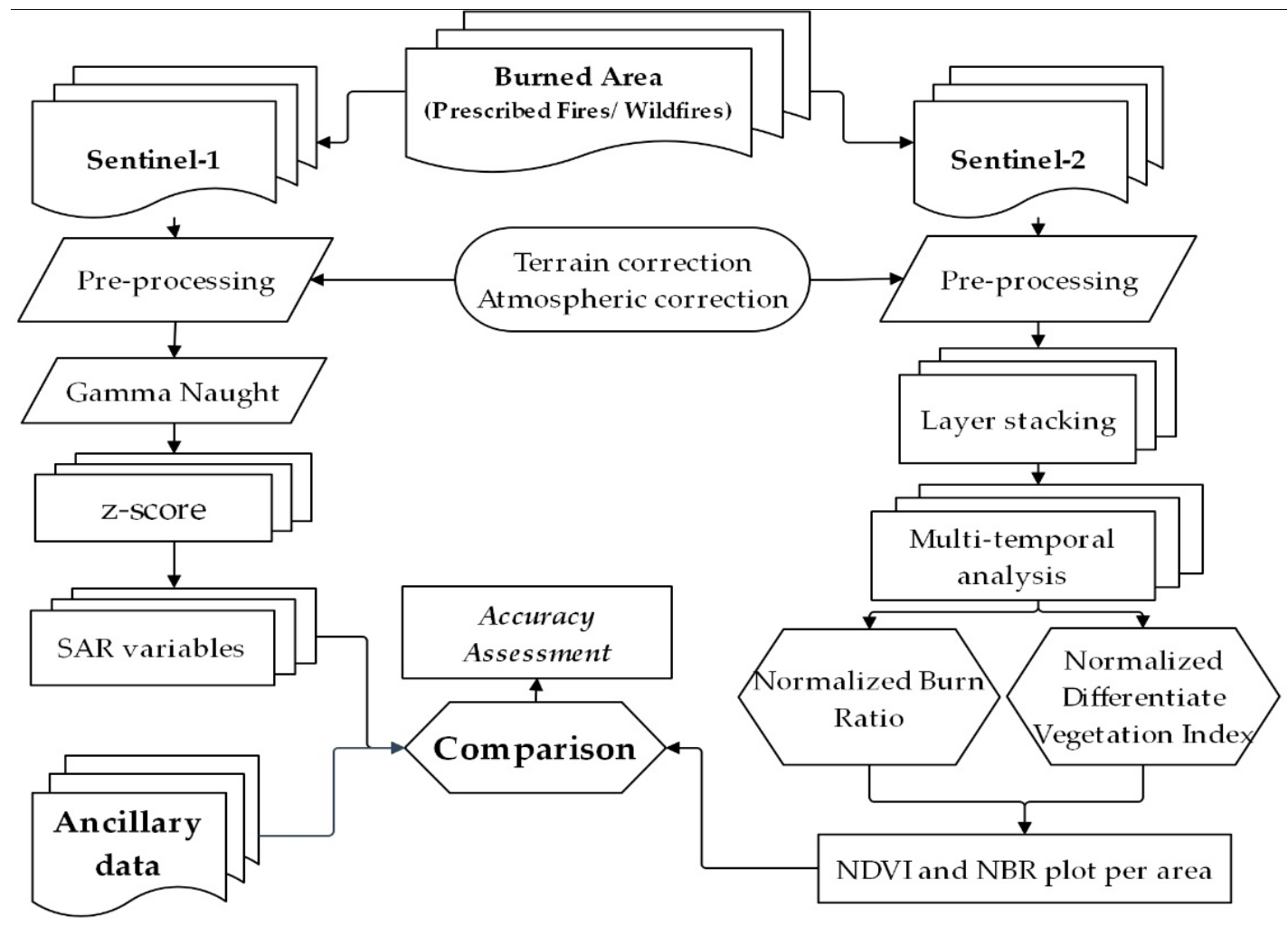

Figure 2. Summary of the methodology used in this paper.

\section{Results}

3.1. NDVI

Table 3 shows the NDVI values prior to and after wildfires and prescribed fires over the study area. A decrease in the NDVI may sometimes be linked to an increase in water stress, with the resulting increase in the risk of fire. According to Table 3, a "mean before fire" was calculated by utilizing values that had previously stabilized from all prior data before the fire, indicating that if in the past that same polygon had experienced a fire, it was excluded from the "mean before fire" calculation. For the "minimum after a wildfire," we used the minimum value of the 40th and 60th percentile (the median) after a wildfire, and we took into consideration all pixels inside each region. Since it is less sensitive to outliers, we selected the 40th and 60th percentile (e.g., unburned parts) [45,46]. The "days for recovery" were computed using the 40th and 60th percentile value of the first day of the fire until the day when the 60th percentile value reaches the "mean before the fire." In 
the end, the intensity of the fire in that region was determined by the difference between Minimum and Mean ("Min-Mean").

Table 3. Each polygon utilized in the NDVI studies was given its own set of data.

\begin{tabular}{cccccccc}
\hline \multirow{2}{*}{ Samples } & \multicolumn{2}{c}{ Regeneration } & \multicolumn{2}{c}{ Before Fire } & \multicolumn{2}{c}{ After Fire } \\
\cline { 2 - 6 } (Min-Mean) \\
\cline { 2 - 7 } No of Days & Dates & Mean & SD & Mean & SD \\
Summer_18_1 & 48 & $2018 / 05 / 02$ & 0.554 & 0.057 & 0.339 & 0.025 & 0.215 \\
Summer_19_3 & 93 & $2019 / 05 / 06$ & 0.570 & 0.073 & 0.363 & 0.026 & 0.207 \\
Summer_19_1 & 163 & $2019 / 07 / 12$ & 0.712 & 0.075 & 0.335 & 0.023 & 0.377 \\
PF_18_1 & 34 & $2018 / 07 / 20$ & 0.681 & 0.065 & 0.275 & 0.021 & 0.406 \\
PF_18_6 & 432 & $2018 / 05 / 14$ & 0.657 & 0.082 & 0.470 & 0.031 & 0.187 \\
PF_18_12 & 152 & $2018 / 05 / 18$ & 0.611 & 0.056 & 0.303 & 0.020 & 0.308 \\
PF_19_1 & 247 & $2019 / 07 / 20$ & 0.705 & 0.070 & 0.389 & 0.027 & 0.316 \\
Autumn_18_2 & 135 & $2018 / 10 / 14$ & 0.657 & 0.045 & 0.393 & 0.027 & 0.264 \\
Autumn_19_1 & 69 & $2019 / 11 / 13$ & 0.698 & 0.059 & 0.355 & 0.026 & 0.343 \\
Autumn_20_6 & 66 & $2020 / 10 / 04$ & 0.739 & 0.041 & 0.418 & 0.028 & 0.321 \\
\hline
\end{tabular}

Figure 3 shows the regeneration time subsequent to prescribed and forest fires in the autumn and summer using NDVI. Wildfires that occurred in the autumn took an average of 223 days to recover from the fire, whereas wildfires that occurred in the summer took an average of 188 days, and prescribed fires took an average of 165 days to recover [47]. The Tukey-Kramer (T-K) test did not identify statistically significant differences in the number of days between the three categories of fires at the $95 \%$ confidence level.

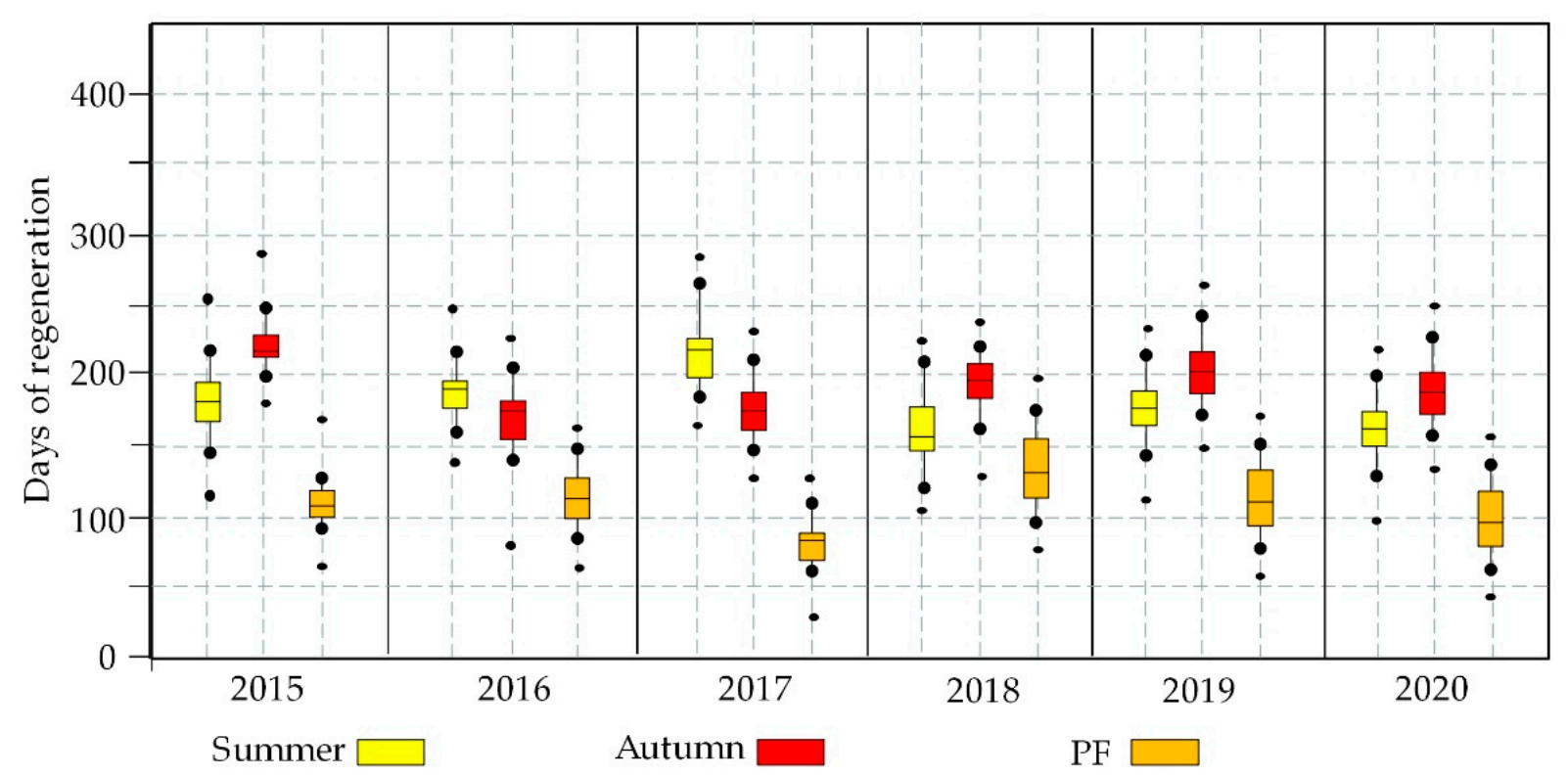

Figure 3. Analysis of days for vegetation recovery from fire using NDVI.

Figure 4 indicates that the average pre- and post-fire NDVI differences for autumn wildfires, summer wildfires, and prescribed fires were $0.398,0.278$, and 0.156 , respectively. The T-K test revealed that the severity of the autumn wildfires was not statistically different from that of the prescribed fires. Summer wildfires, however, differed considerably in severity from prescribed fires, but the difference between summer and autumn wildfires was not found to be statistically significant.

\subsection{NBR}

All of the variables in Table 4 were generated following the previously described approach, but this time using NBR. 


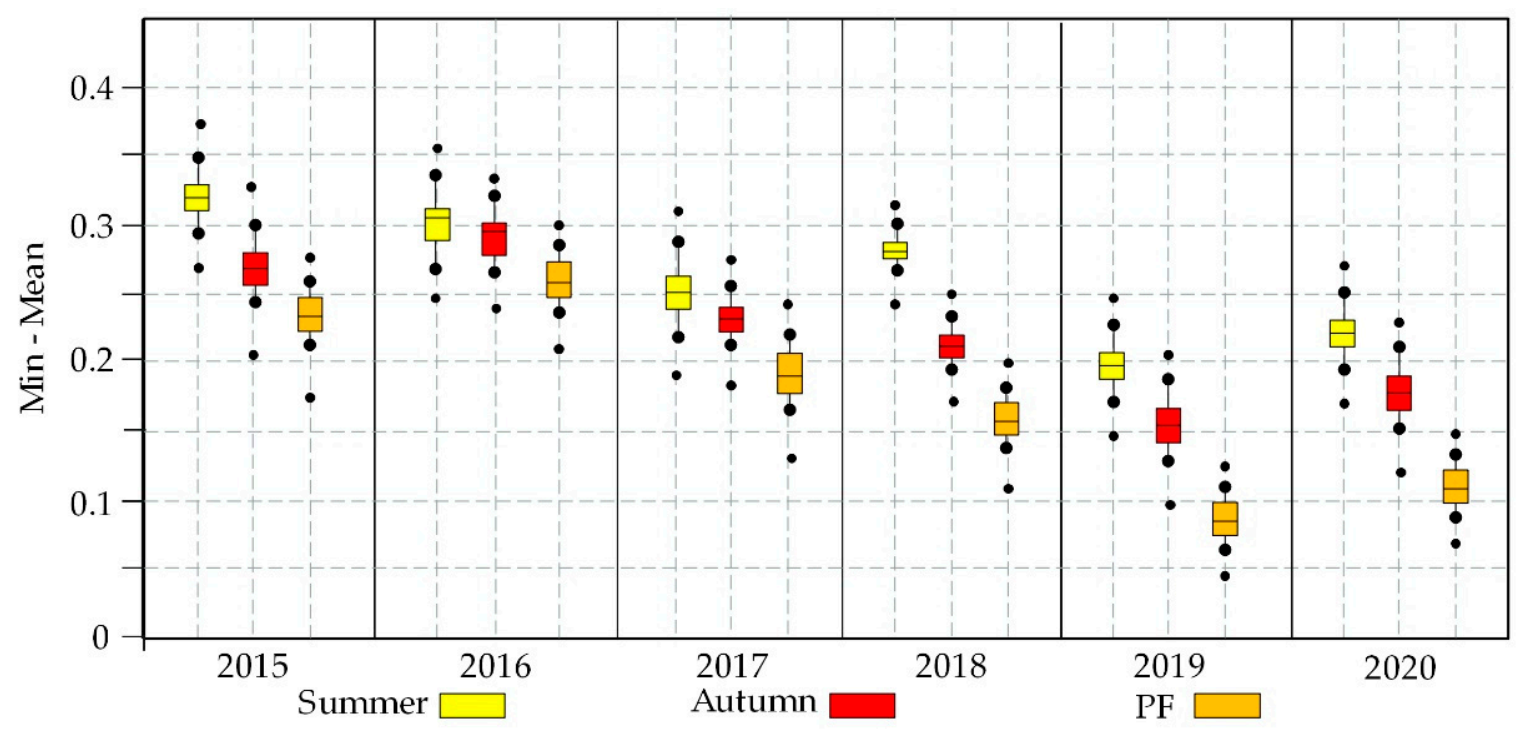

Figure 4. Analysis of days for the severity of the fire using NDVI.

Table 4. Data for each polygon used in NBR analyzes.

\begin{tabular}{cccccccc}
\hline \multirow{2}{*}{ Samples } & \multicolumn{2}{c}{ Regeneration } & \multicolumn{2}{c}{ Before Fire } & \multicolumn{2}{c}{ After Fire } \\
\cline { 2 - 7 } & No of Days & Dates & Mean & SD & Mean & SD & \\
\hline Summer_18_1 & 130 & $2018 / 05 / 01$ & 0.508 & 0.098 & -0.143 & 0.12 & 0.651 \\
Summer_19_3 & 129 & $2019 / 05 / 08$ & 0.581 & 0.061 & -0.322 & 0.23 & 0.903 \\
Summer_19_1 & 62 & $2019 / 07 / 18$ & 0.437 & 0.083 & -0.158 & 0.13 & 0.595 \\
PF_18_1 & 34 & $2018 / 07 / 26$ & 0.336 & 0.127 & -0.205 & 0.15 & 0.541 \\
PF_18_6 & 55 & $2018 / 05 / 03$ & 0.350 & 0.154 & -0.125 & 0.11 & 0.475 \\
PF_18_12 & 87 & $2018 / 05 / 28$ & 0.534 & 0.079 & -0.225 & 0.16 & 0.759 \\
PF_19_1 & 49 & $2019 / 07 / 29$ & 0.494 & 0.066 & -0.167 & 0.17 & 0.661 \\
Autumn_18_2 & 15 & $2018 / 10 / 06$ & 0.511 & 0.061 & 0.185 & 0.18 & 0.326 \\
Autumn_19_1 & 24 & $2019 / 11 / 11$ & 0.390 & 0.071 & -0.206 & 0.19 & 0.596 \\
Autumn_20_6 & 111 & $2020 / 10 / 15$ & 0.518 & 0.075 & -0.196 & 0.18 & 0.714 \\
\hline
\end{tabular}

Figure 5 shows that areas with autumn wildfires took an average of 255 days to recover from the fire, whereas areas with summer wildfires and prescribed fires took an average of 310 and 150 days, respectively.

For Figure 6, the difference between pre-fire and post-fire responses for autumn wildfires, summer wildfires and prescribed fires had an average of 0.789, 0.735 and 0.635, respectively. The autumn wildfires were considered by the T-K test of similar severity to the prescribed fires. As for the other index, the severity of summer wildfires was found to be significantly different from the severity of prescribed fires, while no statistically significant difference was found between the autumn and summer wildfires.

\section{3. $S A R$}

The SAR images depict an example from one area for each of the 34 variables. The $Z$-score of each value was calculated using the mean and standard deviation of the previous 34 values; a Z-score more than three was considered substantially different. When the 34 variables were analyzed, the variable VVnormDiffVH p_95 (NSR p_95) produced the best results $(p$-value $=0.003)$, detecting fire events 20 times out of the 40 areas $(50 \%$ of correct responses) when comparisng with the data from CDA. VVnormDiffVH_p60, VH_p80, VH_p95, VV_p60, VV_p80, VV_p95, VH_p60, VVdivVH_p80, VVdivVH_p95, VVdivVH_p80, VVdivVH_p95, VVdivVH_p80, VVdivVH_p95, VVdivVH_p80, VVHRange_p95p20, VHRange_p95p5, VVRange_p80p40, and VVRange_p95p20 had more incorrect reactions to fires, with an average of just four instances of proper replies to fires. 


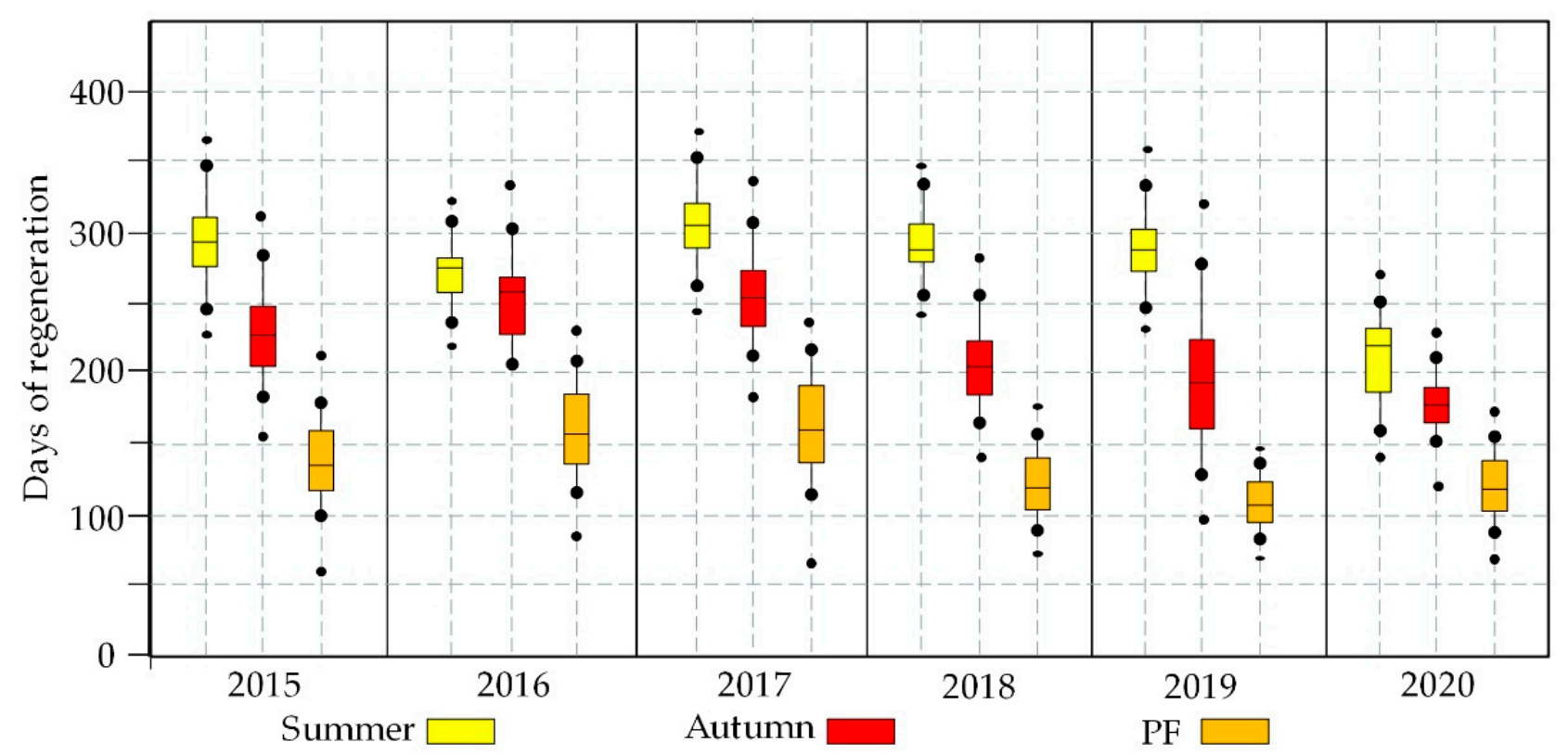

Figure 5. Analysis of days for vegetation recovery from fire using the NBR.

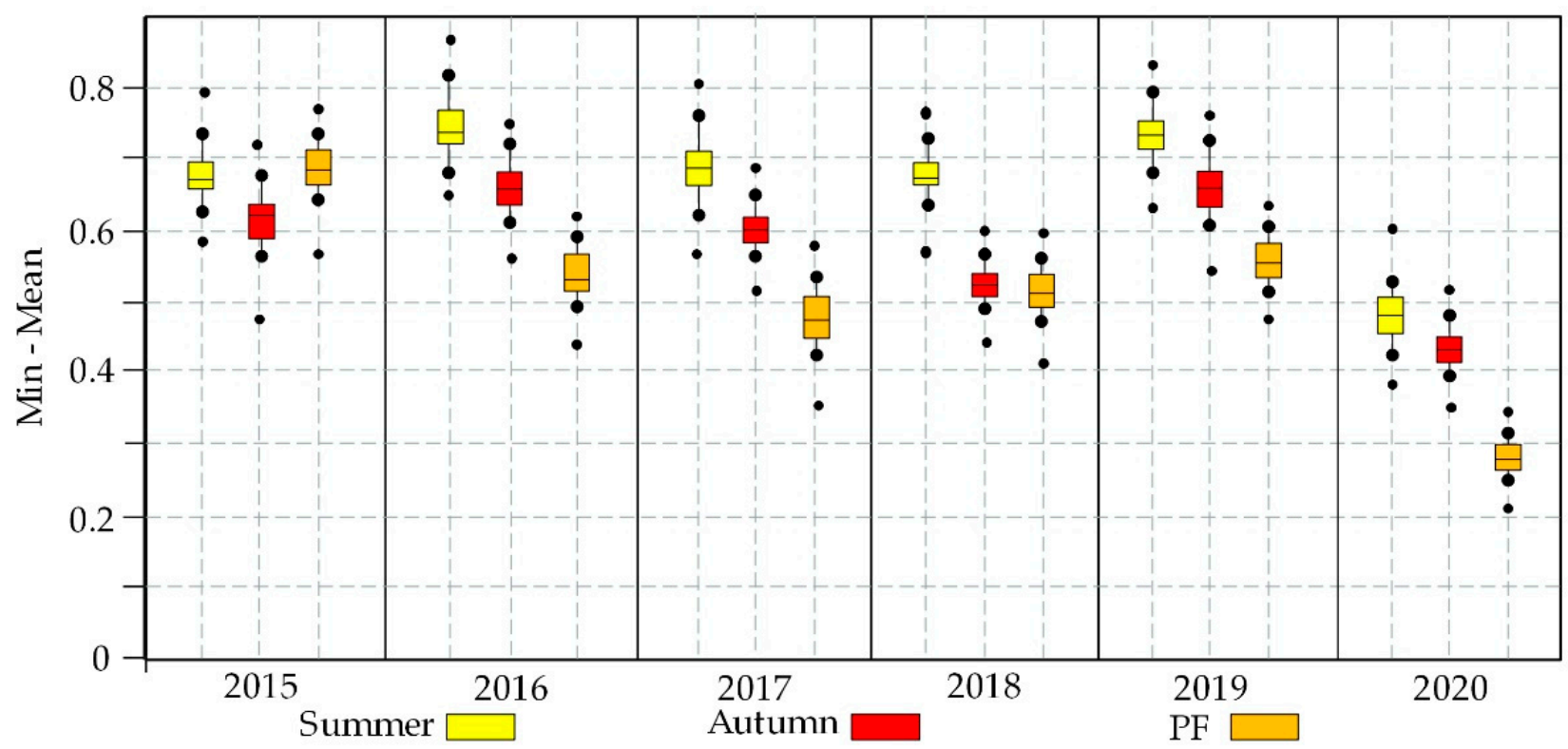

Figure 6. Results of fire severity levels using NBR.

Time series analysis techniques developed for optical imagery are somewhat applicable, although SAR characteristics of backscatter sensitivity to structure and moisture warrant a closer look at new methods. As is typical for deforested areas at C-band, lower backscatter at higher variability is observed in the C-band profile after the deforestation event. This disturbance observation can be identified from the longer trends visible compared to more short-term random noise due to moisture variations. After applying a kernel filter to smooth the time series somewhat, a cumulative sum curve can be constructed from the residuals of the time series data minus the mean observation of the entire time series.

Figure 7 shows the smoothed time series profile and the mean of the time series SAR data used to calculate the response of fire. The cumulative sum of the response is shown as the peaking red curve in the bottom panel. A way to establish the validity and significance of a candidate change point is to perform an analysis in which the time steps are randomly reordered and cumulative sums of the randomized response are computed. 
If the randomization $(n>0.005)$ shows few or no curves reaching the same maximum value of the peak of the cumulative sum curve (which is the change point in time) the point can be labeled valid. As can be seen in Figure 7, the 34-fold SAR variables shows that all randomized curves are significantly lower in their peak values compared to the candidate change point in the observed time series. Applying this approach to all pixels in the subset results in the identification of change pixels and the detected dates of change. The left panel in this figure shows a multitemporal color composite of Sentinel-1 ascending/descending VV / VH polarization acquisitions from 2015 to 2020. Note that many of the red color tones in this multitemporal composite correspond to the expected and detected deforestation and forest degradation events. However, some red tones also are more associated with changes in agricultural patterns, which were correctly not mapped as forest degradation events, as their time series profiles did not match the type of curves seen in the previous profiles.

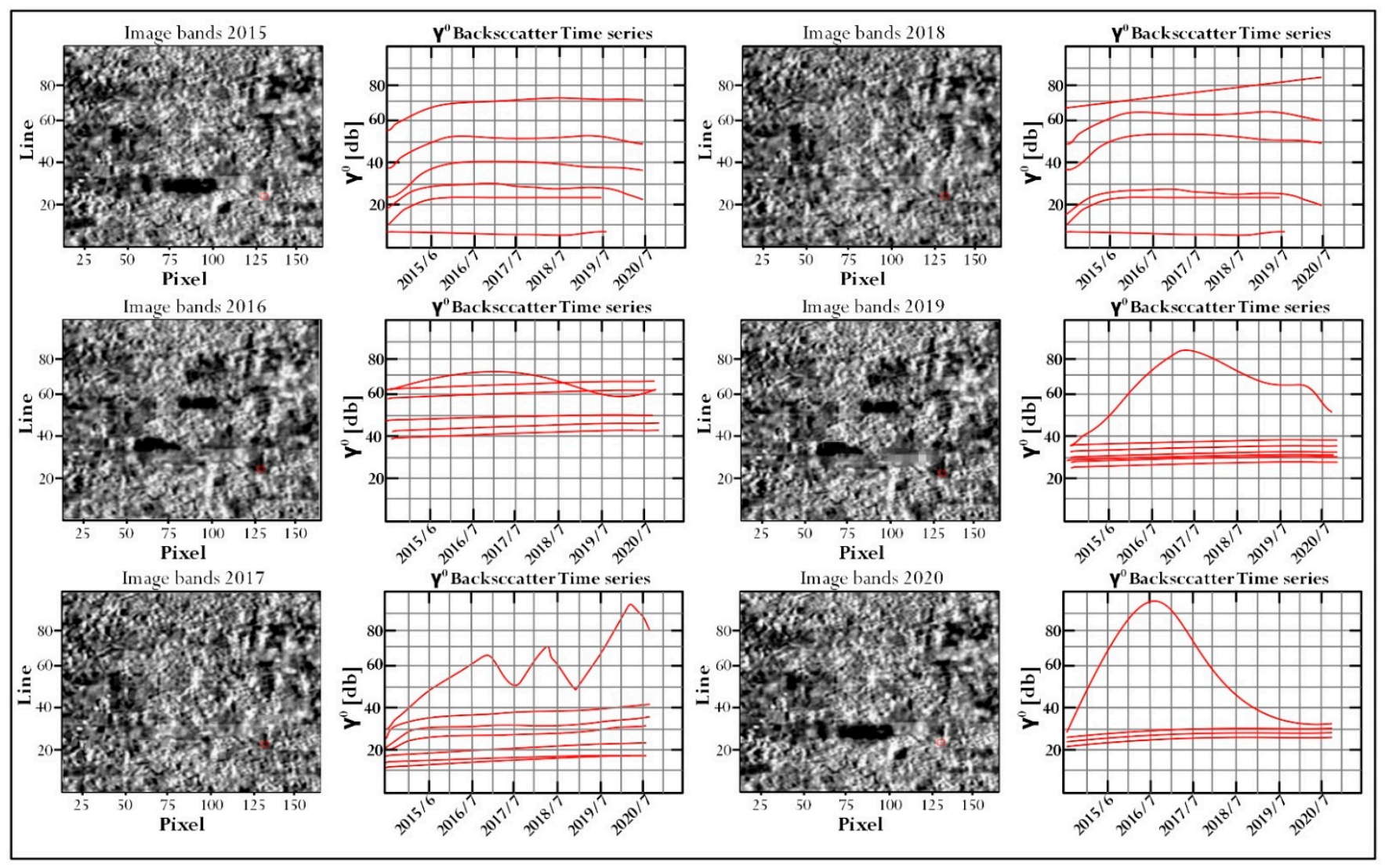

Figure 7. Time series profile of SAR data with associated 34 variables.

\subsection{Comparison between Spectral Indices and $S A R$}

For this part of the study, only the NSR p_80 was used to make the comparison easier. Also, only areas with NDVI and NBR data and SAR data were used (20 in total). Figure 8 shows that the NBR and NDVI plots were adapted to look more similar to the SAR plots and make the visual interpretation easier. For that reason, the plots now are presented with the mean value before the fire and its standard deviation in green. The grey region is the 20th percentile, and the 95th for the black line represents the percentile 60 . The red line indicates the fire event that was the focus of comparison, and the red dotted line, which is shown in some plots, indicates a fire identified by the spectral indices and confirmed by the official data from the CDA. In some cases, it is possible to see that even though the spectral indices behave like there was a fire occurrence (e.g., Summer Wildfire 2019_18, Winter Wildfire 2018_1), there is no indication of a fire with the red dotted line-because, according to the official data from CDA, there was no fire on that day. 

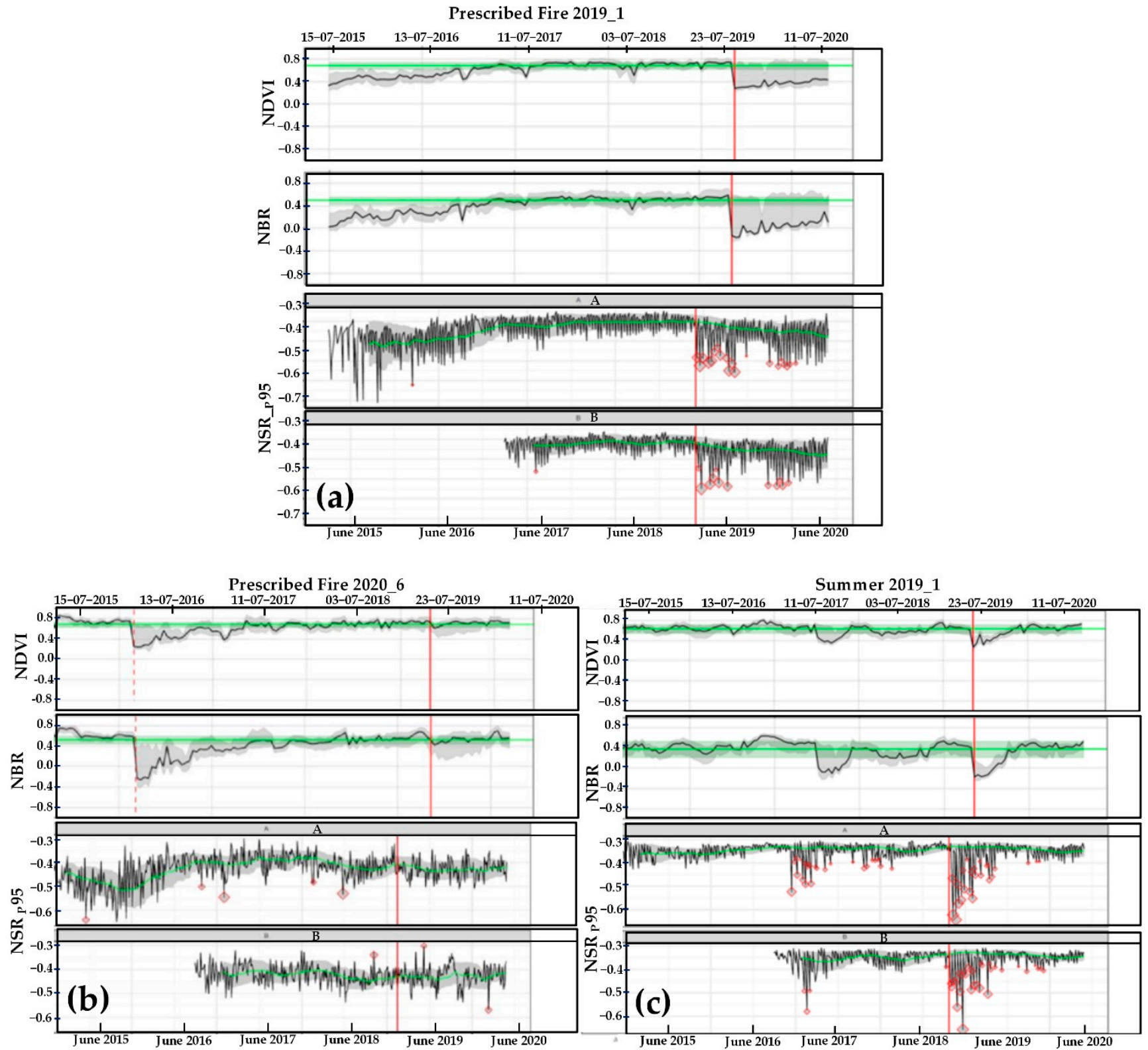

Figure 8. SAR and spectral indices comparison; (a) Top image is an example of SAR NSR_p_95 workings perfectly following the fire event, (b) Left image shows SAR identifying fires inappropriately, (c) Right image shows SAR and spectral indices dropping their values.

Figure 8 shows a sample of two comparisons in which Sentinel-1 performed correctly, another in which SAR did not correctly detect a fire, and a third in which the spectral indices decreased to negative values, indicating that a fire had not occurred in theory, and SAR exhibited the same behavior. When the NSR p_95 and the spectral indices are compared, the rating of correct responses for SAR improves significantly, as SAR responded correctly to NBR 19 out of 20 times (95\% of correct responses), with the "Prescribed Fire $20 \_6$ " being the only one that differed significantly from NBR and NDVI values, and also one of the areas with lower fire severity.

\subsection{Burned Area Comparison}

The NBR-S1, dNBR-S1, NBR-S2, and dNBR-S2 burn severity indices indicated a higher proportion of significant correlations greater than 0.6 within the variables (Table 5). NBR correlation with field attributes immediate post fire effects after capturing post fire images, 
as indicated by comparing the $\mathrm{dNBR}$ and NBR for various individual fires. $\mathrm{dNBR}$ produced better correlations after several weeks had elapsed since burning.

Table 5. Pearson's correlation coefficient between satellite derived and ground based derived results.

\begin{tabular}{ccccccc}
\hline & NBR-S1 & dNBR-S1 & NBR-S2 & dNBR-S2 & NBR-FD & dNBR-FD \\
\hline NBR-S1 & 1.0000 & 0.0735 & 0.8651 & 0.8325 & 0.0536 & 0.0825 \\
dNBR-S1 & 0.0735 & 1.0000 & 0.8932 & 0.6231 & 0.0725 & 0.0539 \\
NBR-S2 & 0.8651 & 0.8932 & 1.0000 & 0.0421 & 0.0852 & 0.0759 \\
dNBR-S2 & 0.8325 & 0.6231 & 0.0421 & 1.0000 & 0.0425 & 0.0679 \\
NBR-FD & 0.0536 & 0.0725 & 0.0852 & 0.0425 & 1.0000 & 0.6481 \\
dNBR-FD & 0.0825 & 0.0539 & 0.0759 & 0.0679 & 0.6481 & 1.0000 \\
\hline
\end{tabular}

\section{Discussion}

The variable NSR p95 (VVnormDiffVH_p95) was determined to be the best out of the 34 variables examined to identify the area burned during both wildfires and prescribed fires using SAR imagery from the Sentinel-1 mission. This contrasts with the findings of Stroppiana et al. [48], who showed that VH polarization alone was ineffective in responding to flames. Furthermore, despite the fact that NSR p_95 only correctly responded to fire occurrences $50 \%$ of the time, the approach employed for the identification of fire on official CDA data was accurate $50 \%$ of the time. It didn't accept false positive responses, such as if one value fell without any evidence of fires on CDA's official data [5].

Therefore, $48 \%$ of the times when NSR p_95 showed a fire event or an absence of fires, the presence/absence of fire was confirmed on the official data. Although this was the method used to evaluate what variable would be the best one between all the 34 , once the chosen variable (NSR p_95) was compared with the spectral indices (i.e., NBR and NDVI), the percentage of correct responses increased significantly [49]. When the NSR p_95 and spectral indices were compared, the rating of accurate answers for SAR increased significantly, as SAR replied to NBR 95\% of the time [23]. As a result, if NBR is the most commonly used index for its correct reactions to fire, NSR p_95 might also be a suitable fit. Moreover, in some cases, it is possible to see that even though the spectral indices behave like there was a fire occurrence (e.g., NBR 19_18 summer), there is no indication of a fire in the official data from the CDA.

This issue may be similar to another situation in which official reports do not match the responses of spectral indices. A future study would be required to explore this issue. It is also worth noting that the current study only looked at burned regions with grasses and small shrubs. As a result, future research should concentrate on employing SAR and comparing its values to those of spectral indices under various land-use/land-cover types.

Even though the number of days to recover from a fire for the three categories (autumn wildfires, summer wildfires and prescribed fires) were not found to be statistically different, the autumn wildfires are considered of equivalent intensity when compared to the prescribed fires. Summer wildfires, however, are very different from prescribed fires, whereas autumn fires are comparable. As a result, it may be claimed that summer wildfires have a greater impact on the surface, but this has no bearing on the time it takes to recover [50].

Because forest managers lack the means to treat the necessary area of the landscape every year, the fact that autumn wildfires are equivalent in severity to prescribed fires, this might be exploited to their advantage. Autumn wildfires might thus be utilized as a treatment to mitigate the severity of summer wildfires, but it is critical to remember that there is no prior delimitation for any wildfire, and the danger to people and infrastructure must still be considered, even if the blaze is of moderate severity.

\section{Conclusions}

This paper found the variable NSR p95 to be adequate to identify burned areas in the study region. It is worth noting that the SAR variable NSR p_95 was initially considered 
as correctly responding to fire events only $48 \%$ of the times where the official fire data from CDA was used as support, but after comparing the SAR values to NBR values, the percentage of "right" responses increased significantly-to $95 \%$. That could be either due to a real difference between NBR and the official fire data, or it could be due to bias. In order to investigate this issue diminishing the human bias, the comparison between NSR p_95 and NBR could be automatized in future studies.

Second, autumn wildfires have a severity close to the severity of prescribed fires. Therefore, they could reduce summer wildfires as far as they are controlled. What can be concluded from this finding is that meteorological conditions are responsible for defining the severity of fires since all other variables (altitude, slope, aspect, area, shape, and land use) were equal or similar for all areas analyzed.

Future studies may build upon our work by introducing and considering other recovery parameters like species composition to enhance the reliability of the method.

Author Contributions: Conceptualization, A.T.; methodology, A.T.; software, A.T.; validation, A.T. and H.S.; formal analysis, A.T.; investigation, A.T. and H.S.; resources, H.S.; data curation, A.T.; writing—original draft preparation, A.T.; writing—review and editing, A.T., H.S., I.M., A.S.G., A.H., F.M., M.A.S.; visualization, H.S.; supervision, H.S.; project administration, Q.L.; funding acquisition, Q.L. All authors have read and agreed to the published version of the manuscript.

Funding: The work was supported by the National Key Research and Development Program of China (Grant No.2019YFE0127700).

Data Availability Statement: The datasets generated and/or analyzed during the current study are not publicly available due to legal constraints because they are owned by different institutions but are available from the authors on reasonable request.

Acknowledgments: The all authors are grateful to GIS Department of Capital Development Authority, Islamabad, for providing data and metadata related to the prescribed fires, from which the reference data used in this work were derived. We are highly thankful to the unspecified reviewers and editor of journal for their enthusiastic support and valuable suggestions during the review of the manuscript.

Conflicts of Interest: The authors declare no conflict of interest.

\section{References}

1. Bastarrika, A.; Alvarado, M.; Artano, K.; Martinez, M.P.; Mesanza, A.; Torre, L.; Ramo, R.; Chuvieco, E. BAMS: A tool for supervised burned area mapping using landsat data. Remote Sens. 2014, 6, 12360-12380. [CrossRef]

2. Curt, T.; Borgniet, L.; Bouillon, C. Wildfire frequency varies with the size and shape of fuel types in southeastern France: Implications for environmental management. J. Environ. Manag. 2013, 117, 150-161. [CrossRef]

3. Tariq, A.; Shu, H.; Li, Q.; Altan, O.; Khan, M.R.; Baqa, M.F.; Lu, L. Quantitative Analysis of Forest Fires in Southeastern Australia Using SAR Data. Remote Sens. 2021, 13, 2386. [CrossRef]

4. Tariq, A.; Shu, H.; Siddiqui, S.; Mousa, B.G.; Munir, I.; Nasri, A.; Waqas, H.; Lu, L.; Baqa, M.F. Forest fire monitoring using spatial-statistical and Geo-spatial analysis of factors determining forest fire in Margalla Hills, Islamabad, Pakistan. Geomat. Nat. Hazards Risk 2021, 12, 1212-1233. [CrossRef]

5. Tariq, A.; Shu, H.; Siddiqui, S.; Munir, I.; Sharifi, A.; Li, Q.; Lu, L. Spatio-temporal analysis of forest fire events in the Margalla Hills, Islamabad, Pakistan using socio-economic and environmental variable data with machine learning methods. J. For. Res. 2021, 13, 12. [CrossRef]

6. Baetens, L.; Desjardins, C.; Hagolle, O. Validation of Copernicus Sentinel-2 Cloud Masks Obtained from MAJA, Sen2Cor, and FMask Processors Using Reference Cloud Masks Generated with a Supervised Active Learning Procedure. Remote Sens. 2019, 11, 433. [CrossRef]

7. Mohammadi, F.; Bavaghar, M.P.; Shabanian, N. Forest Fire Risk Zone Modeling Using Logistic Regression and GIS: An Iranian Case Study. Small-Scale For. 2014, 13, 117-125. [CrossRef]

8. Erokhin, S.; Petukhov, A.; Pilyugin, P. Critical Information Infrastructures Security Modeling; IEEE: Piscataway, NJ, USA, 2019; Volume 2019-April, ISBN 9789526865386.

9. Karnieli, A.; Agam, N.; Pinker, R.T.; Anderson, M.; Imhoff, M.L.; Gutman, G.G.; Panov, N.; Goldberg, A. Use of NDVI and land surface temperature for drought assessment: Merits and limitations. J. Clim. 2010, 23, 618-633. [CrossRef]

10. Aronstein, B.N.; Alexander, M. Effect of a non-ionic surfactant added to the soil surface on the biodegradation of aromatic hydrocarbons within the soil. Appl. Microbiol. Biotechnol. 1993, 39, 386-390. [CrossRef] 
11. Kim, E.J.; Lee, S.W. Structural equation model for burn severity with topographic variables and susceptible forest cover. Sustainability 2018, 10, 2473. [CrossRef]

12. Martinis, S.; Twele, A.; Voigt, S. Towards operational near real-time flood detection using a split-based automatic thresholding procedure on high resolution TerraSAR-X data. Nat. Hazards Earth Syst. Sci. 2009, 9, 303-314. [CrossRef]

13. Solano, F.; Di Fazio, S.; Modica, G. A methodology based on GEOBIA and WorldView-3 imagery to derive vegetation indices at tree crown detail in olive orchards. Int. J. Appl. Earth Obs. Geoinf. 2019, 83, 101912. [CrossRef]

14. Giglio, L.; Loboda, T.; Roy, D.P.; Quayle, B.; Justice, C.O. An active-fire based burned area mapping algorithm for the MODIS sensor. Remote Sens. Environ. 2009, 113, 408-420. [CrossRef]

15. Polychronaki, A.; Gitas, I.Z.; Veraverbeke, S.; Debien, A. Evaluation of ALOS PALSAR imagery for burned area mapping in greece using object-based classification. Remote Sens. 2013, 5, 5680-5701. [CrossRef]

16. Boschetti, L.; Roy, D.P.; Justice, C.O.; Humber, M.L. MODIS-Landsat fusion for large area 30m burned area mapping. Remote Sens. Environ. 2015, 161, 27-42. [CrossRef]

17. Akagi, S.K.; Yokelson, R.J.; Wiedinmyer, C.; Alvarado, M.J.; Reid, J.S.; Karl, T.; Crounse, J.D.; Wennberg, P.O. Emission factors for open and domestic biomass burning for use in atmospheric models. Atmos. Chem. Phys. 2011, 11, 4039-4072. [CrossRef]

18. Escuin, S.; Navarro, R.; Fernández, P. Fire severity assessment by using NBR (Normalized Burn Ratio) and NDVI (Normalized Difference Vegetation Index) derived from LANDSAT TM/ETM images. Int. J. Remote Sens. 2008, 29, 1053-1073. [CrossRef]

19. Jenkins, M.; Collins, L.; Price, O.; Penman, T.; Zylstra, P.; Horsey, B.; Bradstock, R. Environmental values and fire hazard of eucalypt plantings. Ecosphere 2016, 7, e01528. [CrossRef]

20. Li, W. Mapping urban impervious surfaces by using spectral mixture analysis and spectral indices. Remote Sens. 2020, 12, 94. [CrossRef]

21. Whittaker, J.; Mercer, D. The Victorian bushfires of 2002-03 and the politics of blame: A discourse analysis. Aust. Geogr. 2004, 35, 259-287. [CrossRef]

22. Zhang, P.; Nascetti, A.; Ban, Y.; Gong, M. An implicit radar convolutional burn index for burnt area mapping with Sentinel-1 C-band SAR data. ISPRS J. Photogramm. Remote Sens. 2019, 158, 50-62. [CrossRef]

23. Xu, F.; Wang, H.; Jin, Y.-Q.; Liu, X.; Wang, R.; Deng, Y. Impact of cross-polarization isolation on polarimetric target decomposition and target detection. Radio Sci. 2015, 50, 327-338. [CrossRef]

24. Axel, A.C. Burned area mapping of an escaped fire into tropical dry forest in Western Madagascar using multi-season Landsat OLI Data. Remote Sens. 2018, 10, 371. [CrossRef]

25. Pal, S.; Ziaul, S. Detection of land use and land cover change and land surface temperature in English Bazar urban centre. Egypt. J. Remote Sens. Sp. Sci. 2017, 20, 125-145. [CrossRef]

26. Chu, T.; Guo, X. Remote sensing techniques in monitoring post-fire effects and patterns of forest recovery in boreal forest regions: A review. Remote Sens. 2013, 6, 470-520. [CrossRef]

27. Rücker, G.; Siegert, F. Burn Scar Mapping and Fire Damage Assessment Using Ers-2 Sar Images in East Kalimantan, Indonesia. Int. Arch. Photogramm. Remote Sens. 2000, 33, 1286-1293.

28. Ahmad, A.; Ahmad, S.R.; Gilani, H.; Tariq, A.; Zhao, N.; Aslam, R.W.; Mumtaz, F. A Synthesis of Spatial Forest Assessment Studies Using Remote Sensing Data and Techniques in Pakistan. Forests 2021, 12, 1211. [CrossRef]

29. Schroeder, W.; Oliva, P.; Giglio, L.; Quayle, B.; Lorenz, E.; Morelli, F. Active fire detection using Landsat-8/OLI data. Remote Sens. Environ. 2016, 185, 210-220. [CrossRef]

30. Khalid, N.; Saeed Ahmad, S. Monitoring Forest Cover Change of Margalla Hills Over a Period of Two Decades (1992-2011): A Spatiotemporal Perspective. J. Ecosyst. Ecography 2015, 6, 174-181. [CrossRef]

31. Shinwari, M.I.; Khan, M.A. Vegetation Comparison of Sacred, Reserved and Unreserved Sites of Rumli Village at Margalla Hills National Park, Islamabad. Pakistan J. Biol. Sci. 2000, 3, 1681-1683. [CrossRef]

32. Tariq, A.; Shu, H.; Siddiqui, S.; Imran, M.; Farhan, M. Monitoring Land Use And Land Cover Changes Using Geospatial Techniques, A Case Study Of Fateh Jang, Attock, Pakistan. Geogr. Environ. Sustain. 2021, 14, 41-52. [CrossRef]

33. Tariq, A.; Shu, H. CA-Markov chain analysis of seasonal land surface temperature and land use landcover change using optical multi-temporal satellite data of Faisalabad, Pakistan. Remote Sens. 2020, 12, 3402. [CrossRef]

34. Collen, B.; Kock, R.; Heinrich, M.; Smith, L.; Mace, G. Biodiversity and ecosystems. In Thinking Beyond Sectors for Sustainable Development; Ubiquity Press: London, UK, 2015; pp. 3-10, ISBN 9280721127.

35. Brooks, M.; Lusk, M. (Eds.) Fire Management and Invasive Plants; US Department of the Interior: Arlington VA, USA, 2008.

36. Iqbal, M.F.; Riaz Khan, M.; Malik, A.H. Land use change detection in the limestone exploitation area of Margalla Hills National Park (MHNP), Islamabad, Pakistan using geo-spatial techniques. J. Himal. Earth Sci. 2013, 46, 89-98.

37. Sowter, A.; Bin Che Amat, M.; Cigna, F.; Marsh, S.; Athab, A.; Alshammari, L. Mexico City land subsidence in 2014-2015 with Sentinel-1 IW TOPS: Results using the Intermittent SBAS (ISBAS) technique. Int. J. Appl. Earth Obs. Geoinf. 2016, 52, 230-242. [CrossRef]

38. Schepers, L.; Haest, B.; Veraverbeke, S.; Spanhove, T.; Borre, J.V.; Goossens, R. Burned Area Detection and Burn Severity Assessment of a Heathland Fire in Belgium Using Airborne Imaging Spectroscopy (APEX). Remote. Sens. 2014, 6, 1803-1826. [CrossRef]

39. Belenguer-Plomer, M.A.; Tanase, M.A.; Fernandez-Carrillo, A.; Chuvieco, E. Burned area detection and mapping using Sentinel-1 backscatter coefficient and thermal anomalies. Remote Sens. Environ. 2019, 233, 111345. [CrossRef]

40. Frey, O.; Santoro, M.; Werner, C.L.; Wegmüller, U. DEM-based SAR pixel-area estimation for enhanced geocoding refinement and radiometric Normalization. IEEE Geosci. Remote Sens. Lett. 2013, 10, 48-52. [CrossRef] 
41. Tarimo, J.A.; Madoffe, S.S.; Bakke, A. The effect of fire on the diversity and abundance of wood-living beetles in a miombo woodland, tanzania. S. Afr. For. J. 2000, 187, 51-57. [CrossRef]

42. Uwe, M.-W.; Jerome, L.; Rudolf, R.; Ferran, G.; Marc, N. Sentinel-2 Level 2a Prototype Processor: Architecture, Algorithms and First Results. In Proceedings of the European Space Agency Living Planet Symposium, Edinburgh, UK, 9-13 September 2013; pp. 3-10.

43. Oduro, K.A.; Mohren, G.M.J.; Peña-Claros, M.; Kyereh, B.; Arts, B. Tracing forest resource development in Ghana through forest transition pathways. Land Use Policy 2015, 48, 63-72. [CrossRef]

44. Hassani, B.; Sahebi, M.R.; Asiyabi, R.M. Oil Spill Four-Class Classification Using UAVSAR Polarimetric Data. Ocean Sci. J. 2020, 55, 433-443. [CrossRef]

45. Zhu, X.X.; Tuia, D.; Mou, L.; Xia, G.-S.; Zhang, L.; Xu, F.; Fraundorfer, F. Deep Learning in Remote Sensing: A Comprehensive Review and List of Resources. IEEE Geosci. Remote Sens. Mag. 2017, 5, 8-36. [CrossRef]

46. Tansey, K. Vegetation burning in the year 2000: Global burned area estimates from SPOT VEGETATION data. J. Geophys. Res. 2004, 109, D14S03. [CrossRef]

47. Jagdhuber, T.; Stockamp, J.; Hajnsek, I.; Ludwig, R. Identification of Soil Freezing and Thawing States Using SAR Polarimetry at C-Band. Remote Sens. 2014, 6, 2008-2023. [CrossRef]

48. Stroppiana, D.; Calò, F.; Imperatore, P.; Pepe, A.; Boschetti, L.; Brivio, P.A.; Lanari, R. Integration of Sentinel-1 and Sentinel-2 images for detecting burned vegetation in California. In Proceedings of the 11th EARSeL Forest Fires SIG Workshop, New Trends in Forest Fire Research Incorporating Big Data and Climate Change Modeling, Chania, Greece, 25-27 September 2017; pp. 25-28.

49. Stroppiana, D.; Bordogna, G.; Carrara, P.; Boschetti, M.; Boschetti, L.; Brivio, P.A. A method for extracting burned areas from Landsat TM/ETM+ images by soft aggregation of multiple Spectral Indices and a region growing algorithm. ISPRS J. Photogramm. Remote Sens. 2012, 69, 88-102. [CrossRef]

50. Tariq, A.; Riaz, I.; Ahmad, Z. Land surface temperature relation with normalized satellite indices for the estimation of spatiotemporal trends in temperature among various land use land cover classes of an arid Potohar region using Landsat data. Environ. Earth Sci. 2020, 79, 40. [CrossRef] 